Boletín de la Asociación de Geógrafos Españoles, 77, 80-110

ISSN: 0212-9426

Enlace DOI: http://dx.doi.org/10.21138/bage. 2535

Cómo citar este trabajo: Hernández Carretero, A. M., Burgui, M., Velázquez de Castro, F., \& Corrales Vázquez, J. M. (2018). ¿Responden los libros de texto a las demandas de la educación ambiental? Un análisis para la educación secundaria. Boletín de la Asociación de Geógrafos Españoles, 77, 80-110. doi: http://dx.doi.org/10.21138/bage.2535

\title{
¿Responden los libros de texto a las demandas de la educación ambiental?
}

\section{Un análisis para la educación secundaria}

Do textbooks respond to the requirements of Environmental Education?

An analysis in Secondary Education

\author{
Ana María Hernández Carretero \\ ahernand@unex.es \\ Departamento de Didáctica de las Ciencias Sociales \\ Universidad de Extremadura (España)
}

Mario Burgui

mario.burgui@uah.es

Cátedra de Ética Ambiental "Fundación Tatiana Pérez de Guzmán el Bueno"

Universidad de Alcalá (España)

Federico Velázquez de Castro

naturambiente12@yahoo.es

Asociación Española de Educación Ambiental (España)

José María Corrales Vázquez

corrales@unex.es

Departamento de Didáctica de las Ciencias Experimentales

Universidad de Extremadura (España) 


\title{
Resumen
}

La educación ambiental es indispensable en los curricula educativos, por lo que se recoge en todos los manuales escolares. El enfoque con el que se abordan los contenidos y problemáticas medioambientales influye en los valores, actitudes y compromisos adquiridos por los estudiantes. Este es nuestro objetivo: analizar cómo se tratan los contenidos ambientales, el enfoque sobre las relaciones ser humano-naturaleza, qué valores se fomentan, qué acciones se promueven, etc. Para ello revisamos los libros de texto de Educación Secundaria de las materias de Ciencias de la Naturaleza y Ciencias Sociales, de uso más común en España. Si bien los resultados revelan que los contenidos medioambientales son visibles en todos los manuales, se observa que se fomenta más el aprendizaje memorístico de conceptos que la comprensión de su complejidad, se presentan desde un enfoque que prima el uso que los seres humanos hacemos de los recursos naturales, y se fomentan acciones más globales que individuales.

Palabras clave: educación ambiental; libros de texto; Educación Secundaria Obligatoria; enfoques; valores ambientales.

\begin{abstract}
Environmental education is indispensable in educational curricula, this is why it's found in every textbook. The approach that is used to present the contents and the environmental issues influence values, attitudes and responsibilities acquired by the students. This is the aim of our research: to analyse how environmental contents are treated, the focus on human-nature relationship, what values and actions are promoted, etc. For this we review the most used Secondary Education textbooks of natural sciences and social sciences in Spain. The results of our analysis show that environmental contents are visible in all textbooks. Most commonly these textbooks favor memory-oriented activities versus those intending to improve students' understanding of environmental complexity. This knowledge is also presented from an anthropocentric approach, highlighting the instrumental value of natural resources, and promoting actions at the individual level rather than global and social.
\end{abstract}

Key words: environmental education; textbooks; Spanish Secondary Education; approaches; environmental values.

\section{Introducción}

La preocupación internacional por los problemas medioambientales se inicia a mediados del siglo $X X$, coincidiendo con la creación de la Unión Internacional para la Conservación de la Naturaleza (UICN), organismo que comprendió la importancia de la educación y concienciación de la 
sociedad en esta empresa. Desde entonces y hasta ahora, tal como señala Araújo (2000, p. 97): "ya hemos contemplado varias veces el zigzagueante avanzar de la política y la conciencia ambiental", unas veces con grandes progresos y anhelos, y otras, por desgracia, con retrocesos y desilusiones.

Desde la declaración de la UNESCO en 1970 (UNESCO, 1972), pasando por la Carta de Belgrado de 1975 (UNESCO, 1975), la declaración de Tbilisi en 1977 (UNESCO, 1977) o de Moscú en 1987 (UNESCO, 1987), hasta otras más recientes como la Cumbre de Río de Janeiro en 1992 (UNESCO, 1992), la Cumbre Mundial sobre el Desarrollo Sostenible en Johannesburgo en 2002 (UNESCO, 2002) o el Decenio de las Naciones Unidas de la Educación para el Desarrollo Sostenible (EDS) 2005-2014 (UNESCO, 2006), son numerosos los textos internacionales que inciden en que es necesaria una educación en el terreno ambiental, educación que pasa por entender que el medio ambiente es antes que nada un lugar de vida, el lugar donde vivimos, donde nos transformamos y del cual somos parte, por lo que esta educación debe promover la interiorización de valores y actitudes que conlleven cambios de comportamiento con respecto al medio ambiente y la utilización de los recursos.

En definitiva, tal como indica González (1996, p. 27):

[...] se considera que la Educación Ambiental es indispensable para la modificación de actitudes y para desarrollar comportamientos compatibles con un desarrollo sostenible, y, por ello, debe ser introducida en todos los niveles escolares, reexaminando los programas escolares y los métodos de educación y aprovechando, para ello, la experiencia de las $O N G$.

En el Programa de Acción Mundial (GAP) sobre la Educación para el Desarrollo Sostenible (EDS), inaugurado en la Conferencia Mundial de EDS de 2014, se pretende mucho más que la adquisición de conocimiento, valores y teorías relacionados con el desarrollo sostenible, y se incide en la urgencia de fomentar, tanto desde la educación formal como desde la no reglada, la implicación y participación activa de todos para su logro (UNESCO, 2012).

Estas consideraciones y recomendaciones han sido recogidas, en mayor o menor medida, en las distintas leyes educativas de nuestro país desde la aprobación de la LOGSE hasta la ley vigente. En general, se propone que la educación ambiental no debe tratarse en una asignatura suplementaria, sino planteada desde una perspectiva interdisciplinar, que interrelacione contenidos de tipo conceptual, procedimental y actitudinales y fundamentada en estrategias didácticas basadas en la reflexión y el debate, aquellas que parten del análisis de hechos concretos y cercanos. "Ver y juzgar" son, por tanto, parte de la metodología (Velázquez, 2007). 
A su vez, estas consideraciones y recomendaciones explícitas en los currículos educativos deben concretarse en los libros de texto, que se convierten en herramientas mediadoras que traducen y concretan aquellos significados incluidos en el currículo (Occelli y Valeiras, 2013). Su uso e importancia en el proceso educativo dentro del aula explica que el análisis de los manuales escolares sea una línea de investigación vigente en la didáctica, pues, a pesar de la revolución que ha supuesto la introducción de las Tecnologías de la Información y la Comunicación en el proceso educativo, todavía constituyen la fuente principal de contenidos en la dinámica habitual del aula (Choppin, 1992; Gimeno Sacristán, 2005; Occelli y Valeiras, 2013; Woodward y Elliott 1990). A ello hay que sumar que estos manuales son herramientas didácticas que, habitualmente, llevan implícito un gran componente ideológico (Apple, 1993; Carvalho y Clément, 2007; De Puelles, 2007; Eisner, 1992; Ferguson, Collison, Power y Stevenson, 2006; Occelli y Valeiras, 2013). De Paula, De Las Heras, Romero y Cañal (2014) subrayan cómo la diferencia de contenidos en distintos libros de texto puede influir en la atracción que los alumnos sientan por conocer más sobre los temas. Y esta atracción hacia el conocimiento del medio natural, en última instancia, puede llegar a influir en el aprecio que se sienta hacia él.

Algunos estudios (Muñoz y Rubio, 2013; De Paula et al., 2014) se han centrado en valorar los contenidos relacionados con el medio natural en libros de texto de Educación Primaria de editoriales de uso muy habitual, como SM, Santillana y Anaya. Su objetivo es determinar los puntos fuertes y débiles de estos textos a la hora de transmitir conocimientos sobre el medio natural, social y cultural, así como la atención prestada a los animales y plantas, observándose, por lo general, grandes desequilibrios en todos los casos.

En cuanto a la transmisión de valores propiamente ambientales, Botey (2013) advierte que los manuales escolares no transmiten la realidad de los problemas ambientales y sus causas, y, por supuesto, no promueven la reflexión crítica de los alumnos al respecto. En este mismo sentido, Pérez, Pérez y Quijano (2009) destacan que es difícil promover en el alumnado de Educación Secundaria un cambio de actitud respecto al medio ambiente partiendo de la instrucción habitual que se da en la educación secundaria convencional (lo cual incluye tanto a los libros de texto, como a los currículos, metodologías de enseñanza, etc.). García y Martínez (2010) inciden en que los libros de texto presentan una visión muy sesgada de los problemas medioambientales que no permite a los alumnos relacionar la conservación de la biodiversidad con la mejora de su calidad de vida. Por su parte, Mattehws (2012) hace hincapié en el uso de instrumentos apropiados para la enseñanza medioambiental, tales como preguntas, diálogos, debates, etc., que inviten a los 
estudiantes y a los profesores a profundizar en las cuestiones tratadas, discutirlas e investigarlas, y no simplemente a memorizarlas.

El objetivo general que nos planteamos es identificar y caracterizar los valores y actitudes transmitidos por los libros de texto de Educación Secundaria Obligatoria en relación con la educación ambiental. Se trata de analizar desde qué enfoque y posicionamiento se abordan estos valores y actitudes, pudiendo ir desde el antropocentrismo, que, en su versión más extrema, concede a la naturaleza un carácter exclusivamente económico-instrumental, dirigido a la satisfacción de las necesidades humanas, como "mero almacén de recursos, como fuente de materias primas susceptibles de ser transformadas a conveniencia, con las únicas restricciones de la capacidad técnica y la viabilidad económica del proceso" (Chuvieco \& Martín, 2015, p. 92); hasta el biocentrismo, que rechaza la superioridad del ser humano así como la dualidad ser humano/naturaleza, reconoce la interdependencia entre todos los seres y el hecho de que, como individuos y como sociedades, estamos todos inmersos en los procesos cíclicos de la naturaleza, por lo que incentiva la reconstrucción de los lazos con ella (Bilbeny, 2010; Chuvieco \& Martín, 2015). Entre ambos extremos se conforman otras posturas más intermedias tales como el humanismo y otras corrientes de pensamiento basadas en la idea del cuidado de la naturaleza, de un ecodesarrollo y ecoeducación, y no de su explotación y dominación (Marcos, 2001; Chuvieco \& Martín, 2015). En función de dicho enfoque, se asume cierta responsabilidad civil, así como la intervención y participación en temas medioambientales.

Para realizar este trabajo examinamos los manuales correspondientes a las asignaturas de Ciencias Naturales, Ciencias Sociales, Biología y Geología y, también, Geografía e Historia, de aquellas editoriales de uso más común en las aulas según el plan de estudios de la Ley Orgánica 2/2006, de 3 de mayo de Educación (LOE) (BOE 4 de mayo de 2006) y del RD 1631/2006, de 29 de diciembre, (BOE 5 de enero de 2007) por el que se establecen las enseñanzas mínimas correspondientes a la Educación Secundaria Obligatoria. En la actualidad esta Ley y el Real Decreto están derogados por la Ley Orgánica 8/2013, de 9 de diciembre, para la Mejora de la Calidad Educativa (LOMCE) (BOE 10 de diciembre de 2013) y por el Real Decreto 1105/2014, de 26 de diciembre, (BOE, 3 de enero de 2015) por el que se establece el currículo básico de la Educación Secundaria Obligatoria y del Bachillerato. Por tanto, el artículo presenta un análisis de manuales de la ESO ${ }^{1}$ que, aunque ya no están en vigor en la actualidad, puede ser útil para que tanto docentes como educadores e, igualmente, editoriales, reflexionen sobre los valores, actitudes y compromisos

1 Manuales vigentes en el curso 2013/14, fecha en el que se realizó este estudio. Estas publicaciones están siendo sustituidas, de manera progresiva, desde el curso 2015/16. 
ambientales que la educación y los manuales escolares deben perseguir y cómo hacerlo en relación con las nuevas metodologías educativas. Es decir, como objetivos específicos pretendemos conocer si los libros de texto responden a las demandas de los nuevos modelos educativos en general y, en concreto, de la educación ambiental, con el propósito de generar interrogantes que promuevan una renovación de su tratamiento en los libros de texto adscritos a la ley actual (LOMCE). Asimismo, este estudio puede servir de referencia para otros estudios posteriores comparativos entre los manuales vigentes y los adscritos a otras leyes educativas anteriores.

El análisis de los valores y enfoques de la educación medioambiental, tanto en la materia de ciencias naturales como en las ciencias sociales, está en consonancia no solo con los planteamientos de una educación multidisciplinar y con su carácter transversal, sino con la propia definición que hace el Programa de las Naciones Unidas para el Medio Ambiente (PNUMA) sobre el concepto de 'medio', así como con los principios de la Carta de la Tierra y la actual "Ciudadanía Planetaria" (Murga, 2009; Novo y Murga, 2010).

En las últimas leyes educativas de nuestro país, el "medio" se contempla como algo complejo, como el resultado de la interacción entre múltiples factores y donde el ser humano no es solo un elemento más del mismo, sino un agente primordial. Con esta definición se pretende que el alumnado comprenda las relaciones de los seres humanos con el medio, la dinámica y consecuencias de esta interacción, objetivo que no atañe únicamente a las ciencias de la naturaleza, sino con el que deben comprometerse también las ciencias sociales como problemas socioambientales que son (Marrón, 2011).

Para identificar los diferentes enfoques de los libros de texto para la enseñanza del medio ambiente, analizamos y valoramos todos aquellos elementos que constituyen la estrategia educativa y, que sin duda, varían en función de la concepción que se pretende transmitir. Por tanto, no sólo los contenidos y competencias, sino también los recursos y materiales didácticos utilizados, las actividades diseñadas, etc., se ven modificados para responder a las expectativas e ideologías de la educación ambiental.

En definitiva, nos hacemos las mismas preguntas para estos libros de texto que hace Novo (1996, p. 100) para la enseñanza de la educación ambiental en general: "¿Están utilizando al enseñar prácticas interdisciplinarias, metodologías participativas, modos de comunicación no ideologizantes?". Porque, en función de las respuestas, podemos deducir cuál es la meta de la educación ambiental, y cuáles son las raíces éticas de los distintos enfoques que se presentan en los libros de texto. 


\section{Metodología}

En el presente trabajo realizamos una revisión de los contenidos referentes al medio ambiente tanto conceptuales, como procedimentales y actitudinales tratados en manuales educativos de Educación Secundaria, valorando no sólo su presencia en el temario sino sobre todo el enfoque y la visión con la que son presentados y tratados. Hay que aclarar que los contenidos medioambientales a los que hacemos referencia están relacionados con una definición de medio ambiente alejada de los aspectos estrictamente naturales y entendido como un concepto complejo, que interconecta lo social y cultural con la naturaleza, en el sentido que defiende Sauvé (2010), como resultado de la complejidad de las realidades socioecológicas.

\subsection{Muestra}

El muestreo ha tratado de ser lo más amplio y diverso posible. En total se seleccionaron diez de las editoriales españolas más utilizadas en las aulas, tanto de distribución nacional como autonómica: Algaida, ANAYA, ECIR, Editex, Everest, McGraw-Hill, Oxford, Santillana, SM y Vicens Vives (Tabla 1). Asimismo, debido al paulatino auge de los libros digitales, analizamos tanto libros en papel como en distintos soportes: CD, libro con acceso online y libro descargable de Adobe Digital Editions. Los manuales revisados corresponden a publicaciones recientes, a excepción de una de las editoriales del 2008, todas las demás son de 2011 y 2012.

En total se han analizado 63 libros, entre 13 y 19 textos dependiendo del curso (Figura 1). La asignatura con más presencia es Ciencias Naturales, con 22 ejemplares, seguida de Biología y Geología (18), Geografía e Historia (13) y Ciencias Sociales (10). Para su estudio hemos preferido encuadrar cada una de las asignaturas en su materia, así ciencias sociales engloba las asignaturas de "Ciencias Sociales" y "Geografía e Historia" y la materia de ciencias naturales las de "Ciencias Naturales" y "Biología y Geología". Ello obedece a que cada editorial designa a los manuales de manera diferente para cada uno de los cursos, así, algunas editoriales emplean el nombre de Geografía e Historia para la asignatura correspondiente a $3^{\circ}$ de la ESO, y Biología y Geología para $3^{\circ}$ y $4^{\circ}$ de la ESO. Por su parte, para $1^{\circ}$ y $2^{\circ}$ de la ESO, se denominan Ciencias Naturales y Ciencias Sociales. Sin embargo, otras editoriales como Ecir, Santillana y Editex nombran a la asignatura de $1^{\circ}$ de la ESO como Geografía e Historia, y SM utiliza esta denominación para la asignatura de $2^{\circ}$ de la ESO, mientras que Ecir, Algaida y Anaya, utilizan Ciencias Sociales para la asignatura de $4^{\circ}$ de la ESO. La Editorial Editex utiliza Ciencias de la Naturaleza para todos los cursos, incluido $3^{\circ}$ de la ESO. Por su parte, Vicens Vives, nombra a la asignatura de $3^{\circ}$ de la ESO como Biología y Geología, y la de $4^{\circ}$ de la ESO como Ciencias Naturales. 
Tabla 1. Listado de editoriales revisadas y su relación porcentual

\begin{tabular}{|l|c|c|}
\hline Editorial & No libros & Porcentaje (\%) \\
\hline Algaida & 7 & 11,1 \\
\hline Anaya & 7 & 11,1 \\
\hline ECIR & 8 & 12,7 \\
\hline Editex & 6 & 9,5 \\
\hline Everest & 4 & 6,3 \\
\hline McGraw-Hill & 8 & 12,7 \\
\hline Oxford & 5 & 7,9 \\
\hline Santillana & 4 & 6,3 \\
\hline SM & 7 & 11,1 \\
\hline Vicens-Vives & 7 & 11,1 \\
\hline TOTAL & 63 & 100 \\
\hline
\end{tabular}

Fuente: elaboración propia

Estas definiciones no se ajustan en muchos casos a la nomenclatura que se contempla en el Currículo, Real Decreto 1631/2006, de 29 de diciembre, donde se especifica que en $1^{\circ}, 2^{\circ}$ y $3^{\circ}$ de la ESO se cursarán Ciencias de la Naturaleza y Ciencias Sociales, Geografía e Historia, mientras que para $4^{\circ}$ de la ESO las asignatura son Ciencias Sociales, Geografía e Historia y Biología y Geología. Teniendo en cuenta las diferencias existentes en los nombres de las asignaturas según las editoriales, que no coinciden además con los mismos cursos, decidimos agruparlas por materias para su análisis, si bien, para algunas variables valoramos cada una de las asignaturas pues nos permiten responder a algunas cuestiones consideradas de interés.

Figura 1. Número de libros analizados por cursos y asignaturas

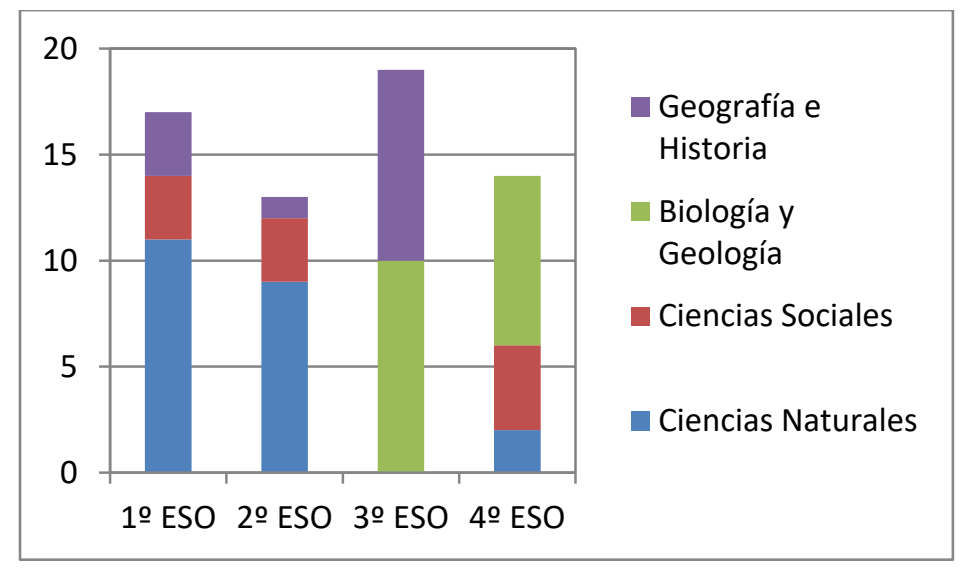

Fuente: elaboración propia 


\subsection{Instrumentos}

Aunque este estudio se enmarca en una metodología de carácter cualitativo, se realizaron, además, algunos análisis estadísticos básicos. Para examinar cada uno de los libros se diseñó una ficha que facilitó la recogida de los datos (Anexo 1), codificados posteriormente con el fin de realizar una valoración cuantitativa de los mismos. Esta codificación se concreta del siguiente modo:

1) Enfoque de los contenidos: Escala de 1 a 5, 1 = Muy Antropocéntrico, 2 = Bastante Antropocéntrico, 3 = Medio, 4 = Bastante Biocéntrico, 5 = Muy Biocéntrico. Esta escala está vinculada con las visiones de antropocentrismo, biocentrismo y humanismo que definimos con anterioridad. En este sentido, asociamos el ítem "muy antropocéntrico" con una visión que concede a la naturaleza tan solo un carácter económico-instrumental, al servicio de la satisfacción de las necesidades humanas. Los dos valores siguientes están vinculados con una postura más matizada, que se autoimpone ciertos límites en la dominación o explotación de la naturaleza, principalmente para evitar problemas para el propio ser humano o para asegurar el sustento de las poblaciones futuras. En una visión contraria, establecemos los ítems "bastante" y "muy" biocéntrico, posturas que exaltan la convivencia con la naturaleza. ${ }^{2}$

2) Contenidos críticos: Escala de 1 a 5, siendo 1 = Nada crítico, $2=$ Poco crítico, $3=$ Medio, $4=$ Bastante crítico, 5 = Muy crítico. En relación con este ítem, identificamos la exposición de contenidos más o menos críticos con las acciones del ser humano en la naturaleza. Así, el valor "nada crítico" estaría acorde con un antropocentrismo muy fuerte, mientras que los ítems "bastante" y "muy crítico" se corresponden a aquellos contenidos que expresan la interrelación existente entre problemas medioambientales/acción humana, llegando incluso a oponerse a esta explotación. Esta postura más crítica se incentiva, a veces, a través de las actividades didácticas "¿Cómo actúa el ser humano sobre el relieve? ¿Crees que esta actuación es positiva o negativa?" (3 ESO).

2 Como ejemplos de las distintas posturas recogemos algunas afirmaciones de los manuales revisados:

Con una visión muy antropocéntrica, asociamos frases como: "Es habitual usar cualquier innovación para mejorar el rendimiento: fertilizantes, pesticidas, invernaderos e incluso semillas modificadas genéticamente" (3 ESO, ciencias sociales), sin mencionar, en ningún caso, los aspectos negativos derivados de su uso.

Ejemplo de un enfoque bastante antropocéntrico: "En numerosos casos, los efectos de estos cambios están resultando muy negativos para la supervivencia de la especie humana ya que las condiciones del planeta Tierra están variando drásticamente" (4 ESO, ciencias naturales) o "es necesario que nos concienciemos de la importancia de realizar un uso racional y sensato del agua para evitar problemas de abastecimiento" $\left(1^{\circ} \mathrm{ESO}\right.$, ciencias sociales). En ambos casos, se hace hincapié en los problemas para el propio ser humano o para asegurar el sustento de las poblaciones futuras. 
3) Valores: Escala de 1 a 5, siendo 1 = Muy pocos valores; 2 = Pocos valores; $3=$ Medio; $4=$ Bastantes valores; 5 = Muchos valores. Esta variable se centra en la promoción de actitudes y valores éticos y morales con los seres que forman parte de la naturaleza, incidiendo en el respeto o la solidaridad hacia otros seres vivos y hacia el propio ser humano como un elemento más del medio.

4) Acción: Dos valores, 1 = no promueve la acción; 2 = promueve acciones concretas, responsables con el medio ambiente, tales como el reciclaje de materiales, el ahorro en el consumo de agua, evitar el vertido de residuos, etc.

5) Tipos de actividades. Dos valores, 1 = actividades memorísticas; 2 = actividades de indagación.

6) Porcentaje de contenidos ambientales. Escala de 1 a 3, siendo $1=$ menos del 10\% respecto del total; 2 = entre el $10 \%$ y el 20\%; 3 = más del 20\% (estos intervalos se han adecuado al bajo porcentaje de contenidos ambientales encontrado en todos los libros analizados).

7) Otros recursos didácticos: Se valora si los libros de texto proponen el uso de otros recursos didácticos a través de enlaces o actividades concretas, tales como salidas extraescolares, medios audiovisuales (vídeos, películas, fotografías, actividades manuales, etc.), medios escritos (otros libros, prensa, artículos científicos), o el uso de las TIC.

\subsection{Procedimiento}

Tras realizar un examen de los datos y las codificaciones mencionadas, se efectuó una exploración estadística descriptiva. A través del programa SPSS Statistics 17.0 se analizaron las frecuencias y la moda para el caso de las variables categóricas: Asignatura, Curso y Editorial; y las medianas y el rango intercuartílico para las ordinales: Enfoque, Contenidos Críticos, Transmisión de Valores, Promoción de la Acción, Tipos de Actividades, Contenidos Ambientales y Tipos de Recursos Didácticos.

En general, se observa que entre los manuales examinados, dominan las posturas de carácter "muy" y "bastante" antropocéntrico en relación con el medio ambiente (Figura 2). A partir de este gráfico analizamos si se trata de una tónica general tanto para las asignaturas de ambas materias como para todos los cursos de la ESO o si por el contrario se reflejan diferencias. 
Figura 2. Representación del enfoque dominante en los libros de texto

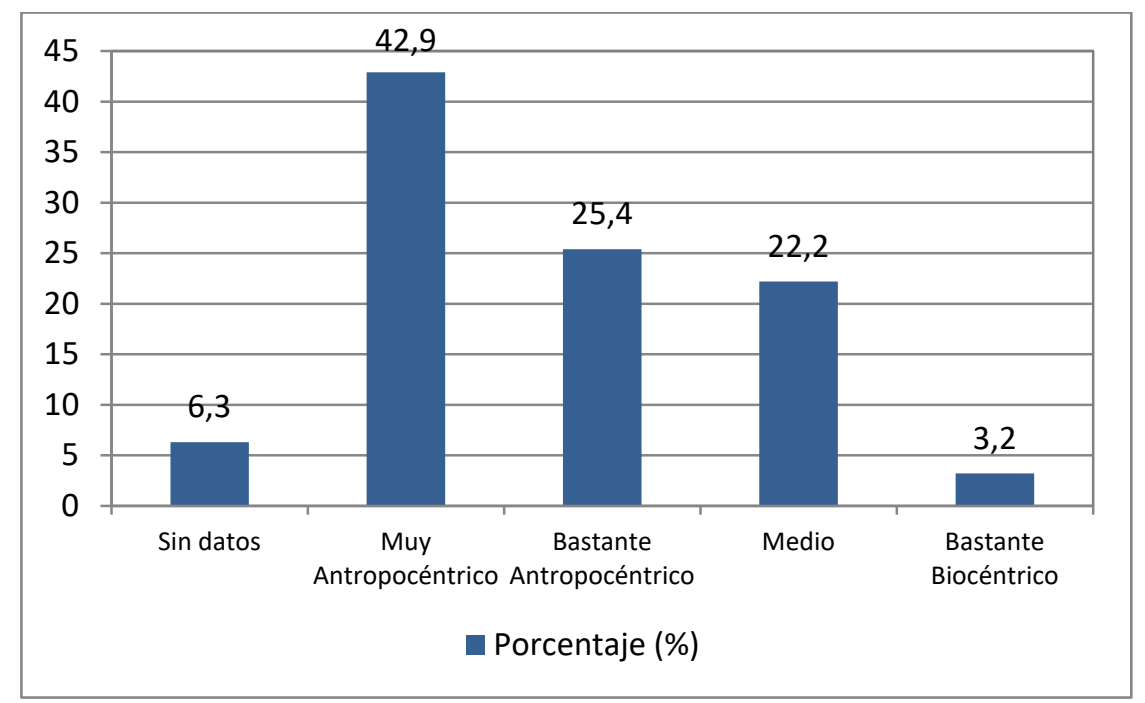

Fuente: elaboración propia

\section{Resultados y discusión}

\subsection{Los contenidos medioambientales por materias y ciclos}

Los contenidos ambientales presentan bajos porcentajes en los libros de texło analizados (Figura 3), por lo general, su presencia está por debajo del $10 \%$ en todos los manuales, a excepción de la asignatura de Biología y Geología que se cursa en $4^{\circ}$ de la ESO de manera optativa (Figura 4), donde los contenidos medioambientales no solo se amplían sino que también se hacen más completos y complejos.

Figura 3. Distribución de los contenidos medioambientales por materias y ciclos educativos

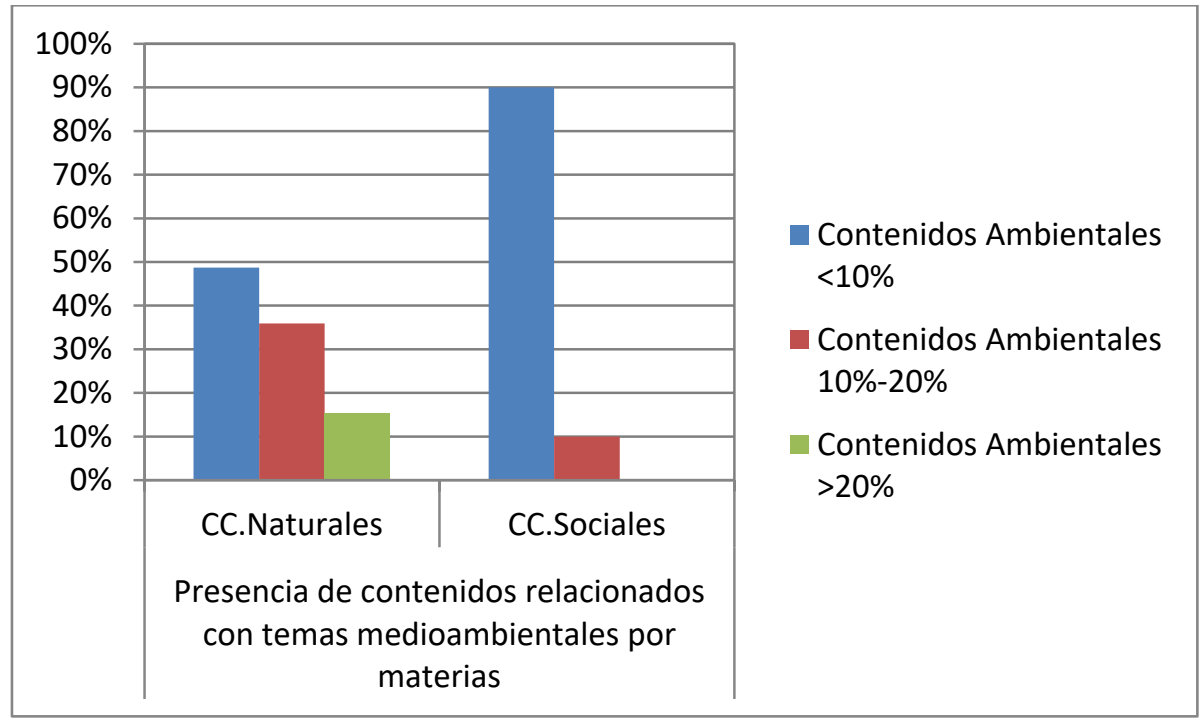


Figura 3. Continuación

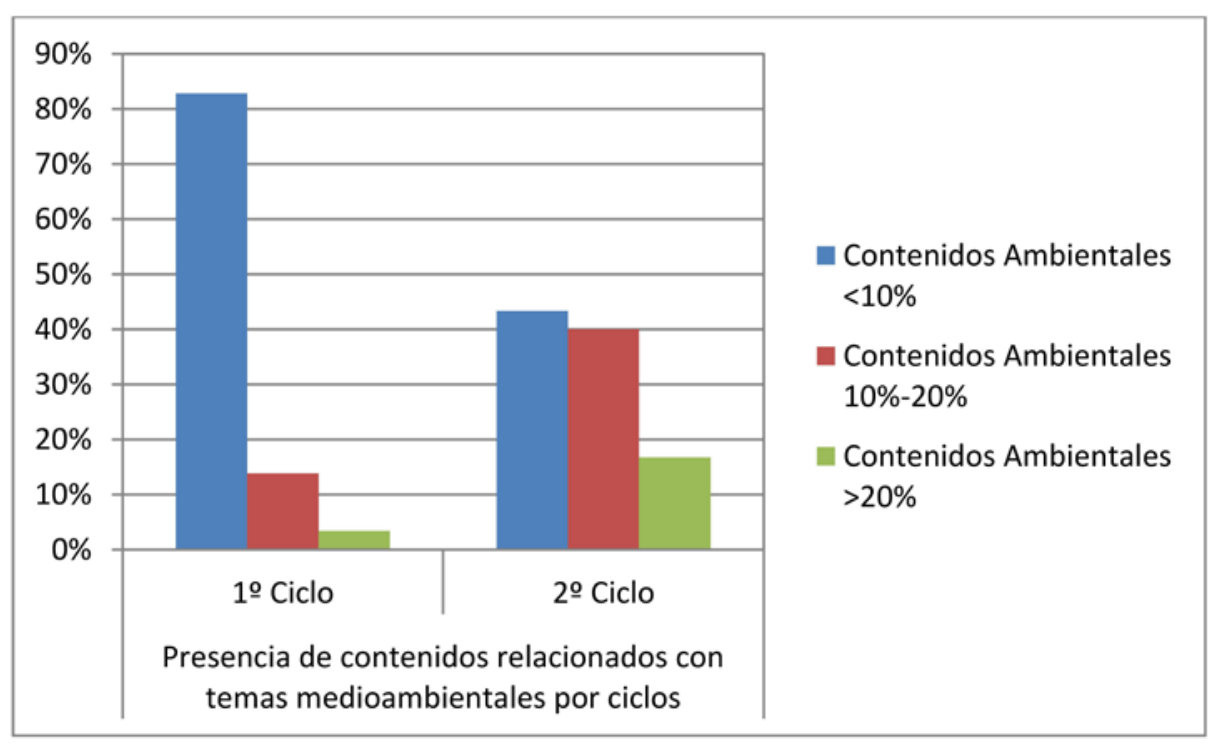

Fuente: elaboración propia

Concretamente, para el primer ciclo de la Educación Secundaria, los contenidos ambientales son marcadamente escasos, mientras que para el segundo ciclo su presencia en los textos aumenta de manera clara, aunque en ningún caso superan el $25 \%$ del total. Asimismo, estos contenidos se tratan sobre todo en la materia de ciencias naturales, mientras que en ciencias sociales su presencia es muy exigua. Es cierto que los contenidos de esta materia son básicamente históricos -los orígenes de la humanidad, las primeras civilizaciones-, pero también en estos temas se puede explicar la interrelación entre el ser humano y el medio a lo largo del tiempo o plantear las consecuencias medioambientales que acarrearon el inicio y desarrollo de la Revolución Industrial. Asimismo, dentro de sus programas se recogen igualmente temas geográficos -el relieve terrestre, el tiempo y el clima, los paisajes de la tierra-, y por lo general, no se presentan contenidos medioambientales $\mathrm{o}$, en su caso, son testimoniales.

Las ciencias sociales revisten un interés especial por cuanto es en el contexto social donde se originan los problemas ambientales y donde se pueden encontrar sus soluciones. Las escuelas que hoy dinamizan más la educación ambiental insisten en vincular de una manera preferente medio ambiente y ciencias sociales, más allá de sus contenidos propios, como el paisaje, la demografía o el urbanismo. Es a partir del conflicto de intereses en el que intervienen varias partes, como podremos comprender con profundidad la génesis, evolución y alternativas a los impactos ambientales. 
Figura 4. Distribución de los contenidos medioambientales por asignatura y cursos
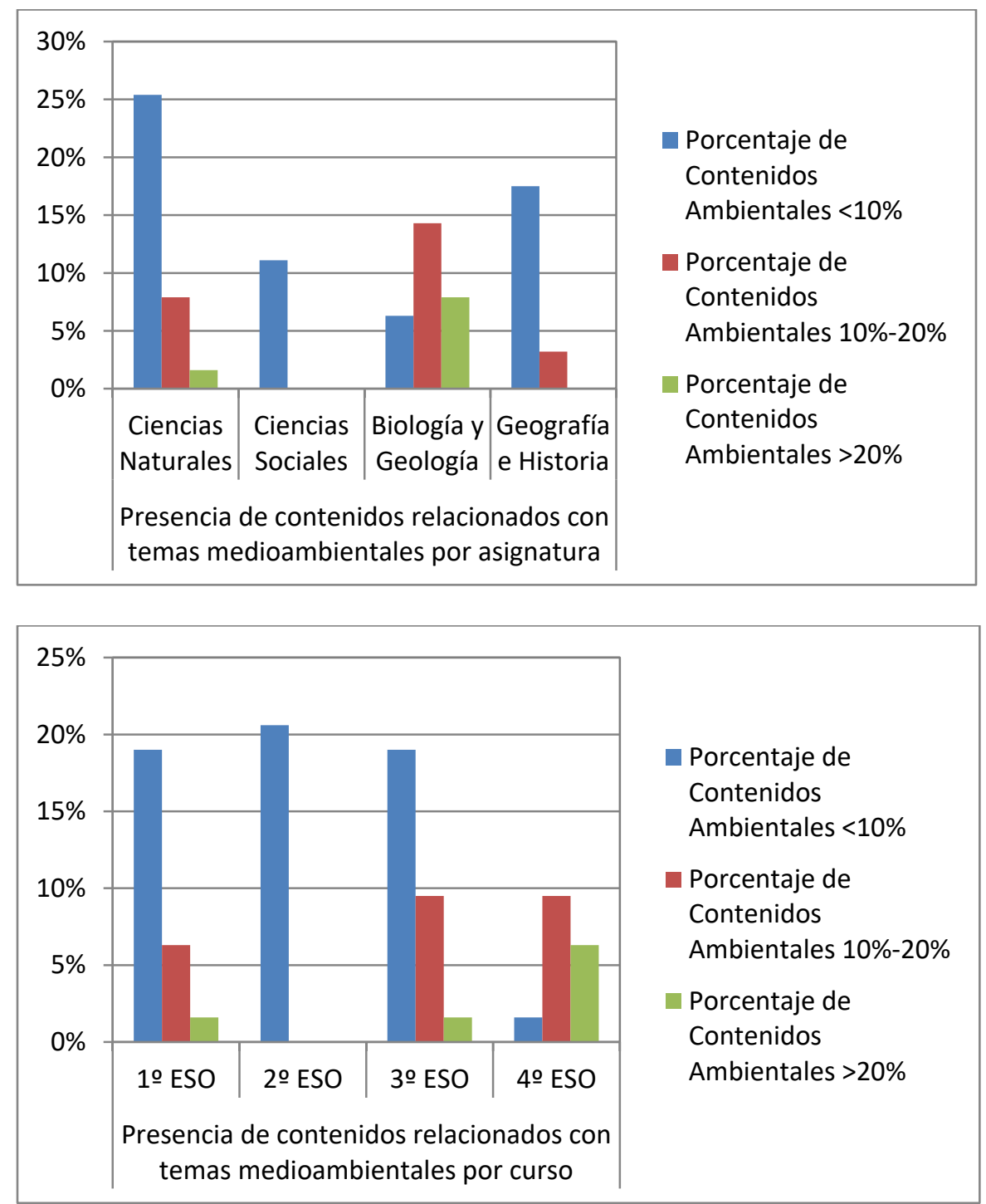

Fuente: elaboración propia

Asimismo, la mayoría de los contenidos referentes al medio ambiente se defienen en definir conceptos, tales como desarrollo sostenible, cambio climático, ecosistema, contaminación; o bien en el reconocimiento o clasificación de objetos, sucesos, etc., que se presentan como afirmaciones científicas absolutas, que no invitan ni a la explicación ni a la reflexión, ni mucho menos al debate y la acción.

Por su parte, los contenidos asociados a la trasmisión de valores medioambientales, preocupados por la degradación de la biodiversidad o los problemas de contaminación, se localizan en la parte final de la unidad didáctica, agrupados en apartados independientes tales como "desarrolla tus competencias", "pon a prueba tus competencias", e incluso en algunos manuales constituyen las 
últimas unidades didácticas. Dado el número de horas de estas materias y lo ajustado de los calendarios escolares es muy fácil que el tema se quede sin tratar por no disponer del tiempo suficiente, quedando su presencia reducida a la nada. Pero, quizá una de las cuestiones más graves de esta separación física entre la problemática ecológica y los contenidos ecocientíficos es que dificulta la comprensión científica de los procesos ecológicos, la relación entre causas y consecuencias, así como la identificación de los factores. Por tanto, consideramos que de esta manera no se aborda la complejidad y la interdependencia de todos los elementos que conforman el medio, ni por supuesto, se entiende la interconexión entre la acción humana y los problemas medioambientales.

\subsection{Enfoque de los contenidos medioambientales}

Esta variable valora el enfoque con el que se presentan los contenidos medioambientales en los libros de texto que, tal como refleja la anterior, son francamente minoritarios en los manuales. Estos resultados reflejan un predominio de los enfoques antropocéntricos, el medio ambiente como recurso, mucho más sobresalientes en la materia de ciencias sociales y para el primer ciclo de la Educación Secundaria que para el segundo (Figura 5).

Este enfoque se refleja no sólo en los contenidos que transmiten, sino también en la manera en cómo se enseñan los contenidos, tanto conceptuales como actitudinales, o en la importancia que se les concede. Así, en algunos manuales, contenidos como -el medio ambiente, el calentamiento global, el desarrollo sostenible- se presentan como puras definiciones científicas que fomentan más un aprendizaje memorístico del concepto que el desarrollo de interpretaciones críticas o de competencias socioambientales entre el alumnado. En otras ocasiones sí se detienen en los problemas derivados de la contaminación ambiental, o de la pérdida de biodiversidad, pero se resaltan sobre todo las consecuencias negativas que pueden tener para el propio ser humano. También documentamos otros casos en los que la problemática ecológica se argumenta como "males menores" a cambio de satisfacer las "necesidades" de la vida humana.

En las unidades didácticas de la materia de ciencias sociales apenas se hace referencia a los problemas medioambientales que generan las industrias, las actividades agrícolas, los procesos de urbanización, las actividades de ocio y turismo, etc.; o como mucho se hace referencia a ellos, pero se asumen, igualmente, como un mal menor y necesario. La producción tecnológica, la actividad agrícola, etc., se enfocan desde una perspectiva económica, un avance social, una mejora de la calidad de vida del ser humano. En ningún párrafo se expresa una preocupación por los problemas medioambientales que ello ha venido generando a lo largo de la historia. 
La visión biocéntrica, aunque muy minoritaria, solo se registra en la materia de ciencias naturales y básicamente en el cuarto curso (Figura 6). En estos casos, los contenidos se hacen eco de la complejidad de los procesos medioambientales a la vez que se perfila el vínculo entre el bienestar humano con el bienestar del planeta. Posiblemente la explicación de esta postura más acorde con un modelo ambiental holista, globalizador, se encuentra en el propio programa de esta asignatura para cuarto de la ESO, donde la dinámica de los ecosistemas abre la visión hacia nuevos elementos, en los que la naturaleza va ganando protagonismo. Sin embargo, ello no se acompaña de la promoción de acciones y medidas medioambientales entre los jóvenes (Figura 8). Es decir, se plantea una alfabetización científica del medio ambiente que pretende una comprensión del mismo como un todo regulado, pero no un cambio de actitud ante la manera de ver y vivir en la naturaleza.

Figura 5. Distribución de los enfoques por materias y ciclos educativos
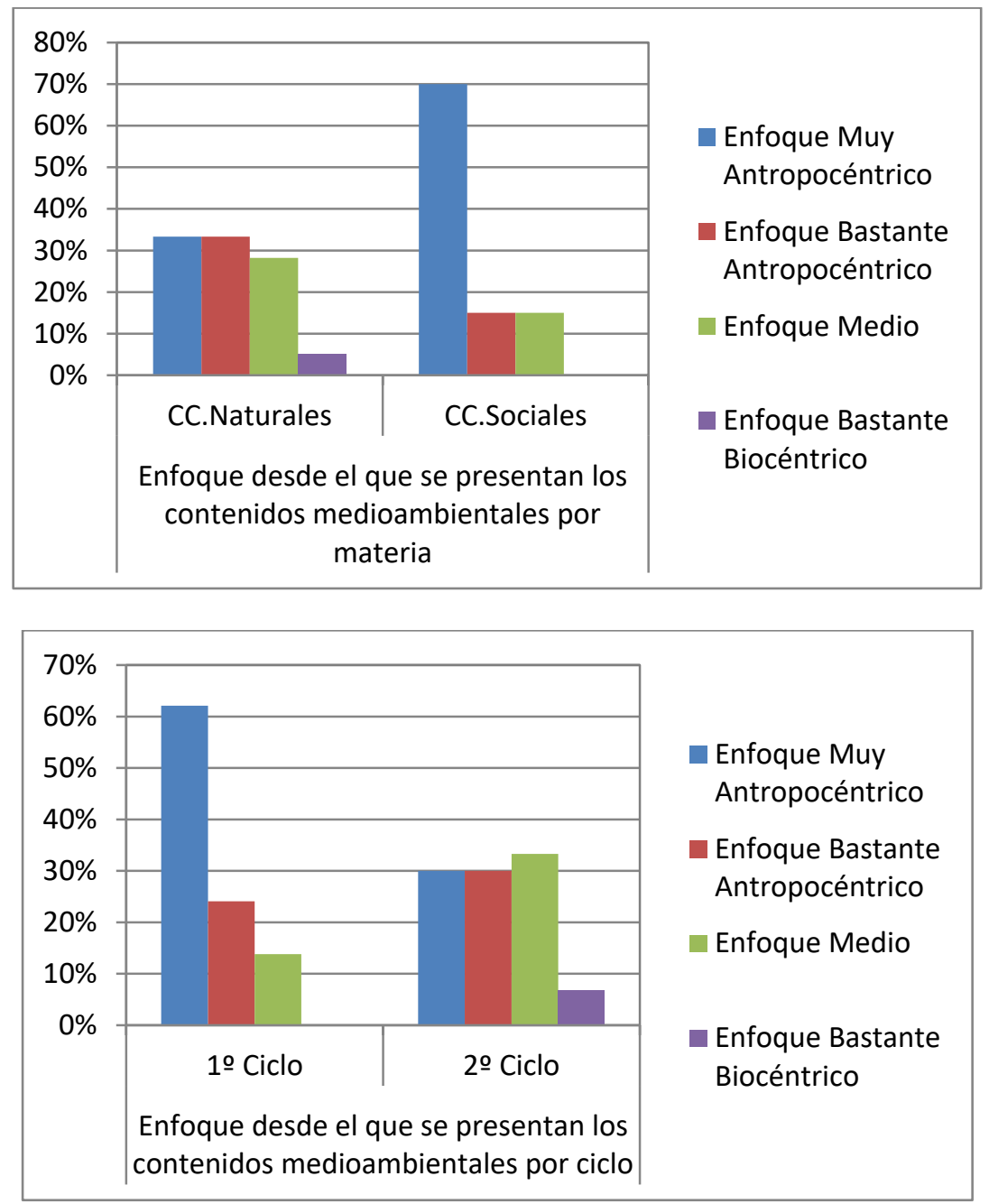

Fuente: elaboración propia 
Figura 6. Distribución de los enfoques por curso

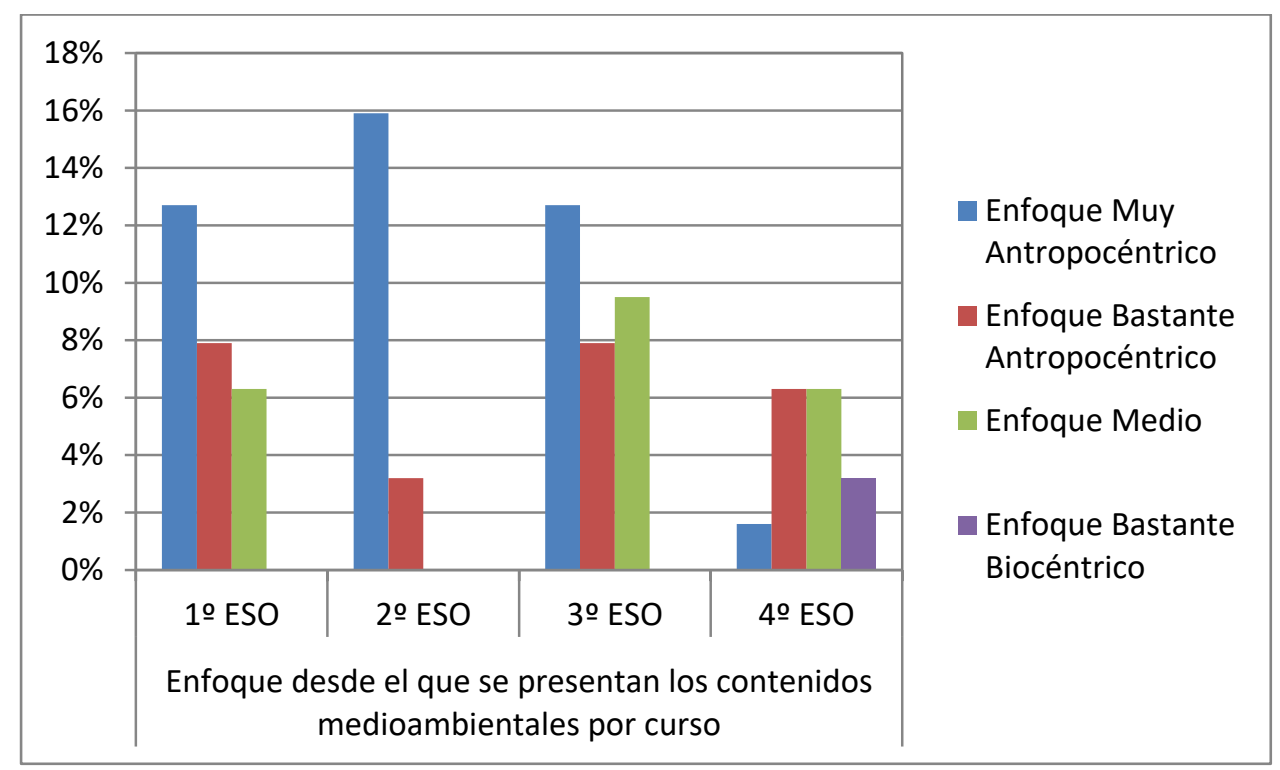

Fuente: elaboración propia

\subsection{Valores y promoción de la acción}

La visión y enfoque con que se presentan los contenidos medioambientales en los manuales escolares se refleja en los valores socioambientales que transmiten y en la promoción de una educación ecociudadana. Para revisar estos aspectos, fijamos dos ítems: uno relacionado con una visión crítica en relación con la actitud del ser humano con respecto a su entorno, el uso que hace de los recursos naturales, el posicionamiento ante la contaminación y los impactos ambientales, el modelo de desarrollo económico, etc.; y otro ético, si el texto incorpora ciertos valores o incita al cambio actitudinal respecto a nuestra relación con el entorno.

Los resultados revelan que la mayoría de estos manuales no fomentan el desarrollo de la autocrítica en el alumnado, así como tampoco unos hábitos de consumos responsables y sostenibles en la vida cotidiana con el medio ambiente, y, por supuesto, no promueven la reflexión-acción (Figura 7). 
Figura 7. Promoción de valores y fomento de la acción por materias y ciclos
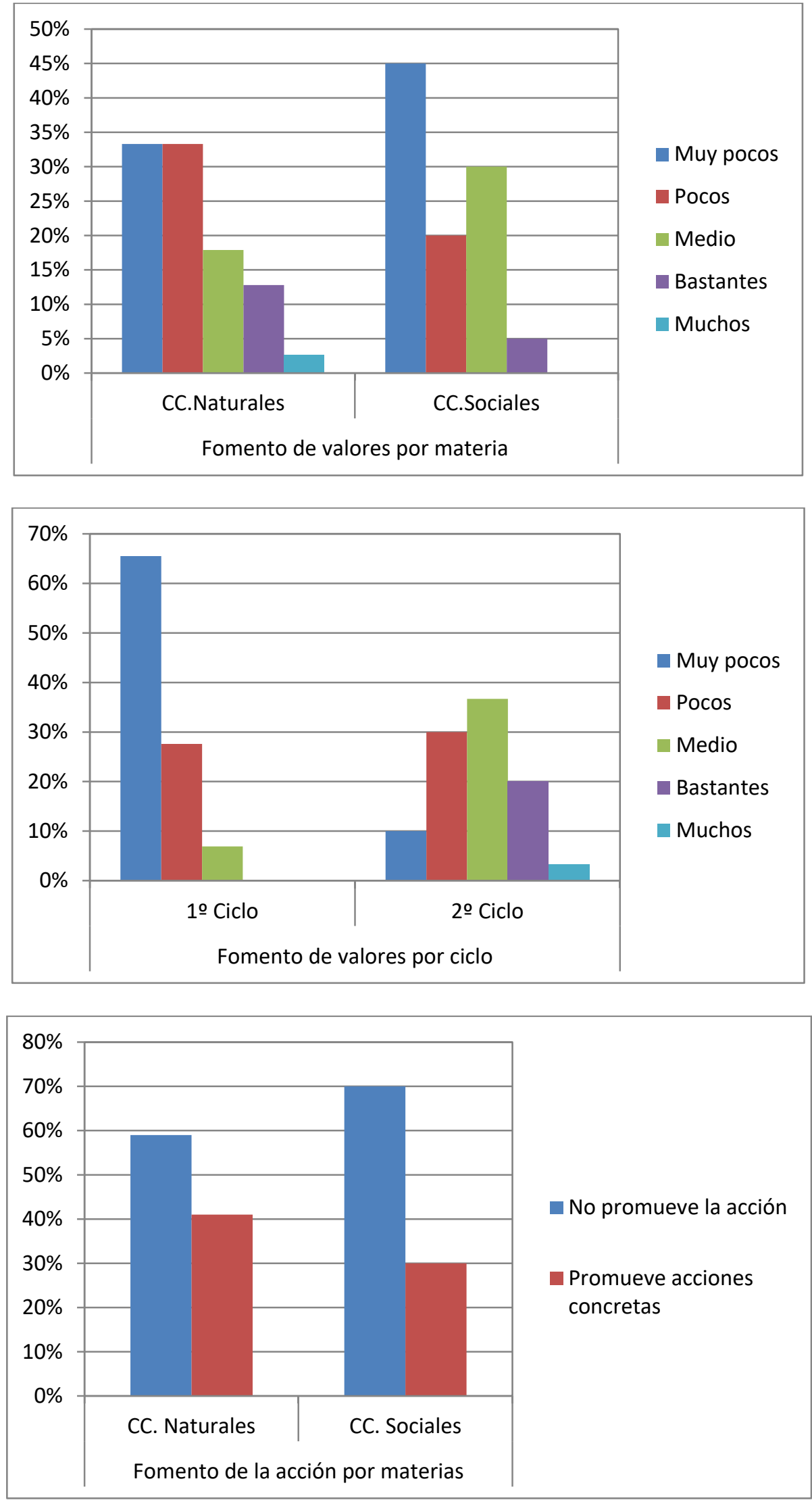
Figura 7. Continuación

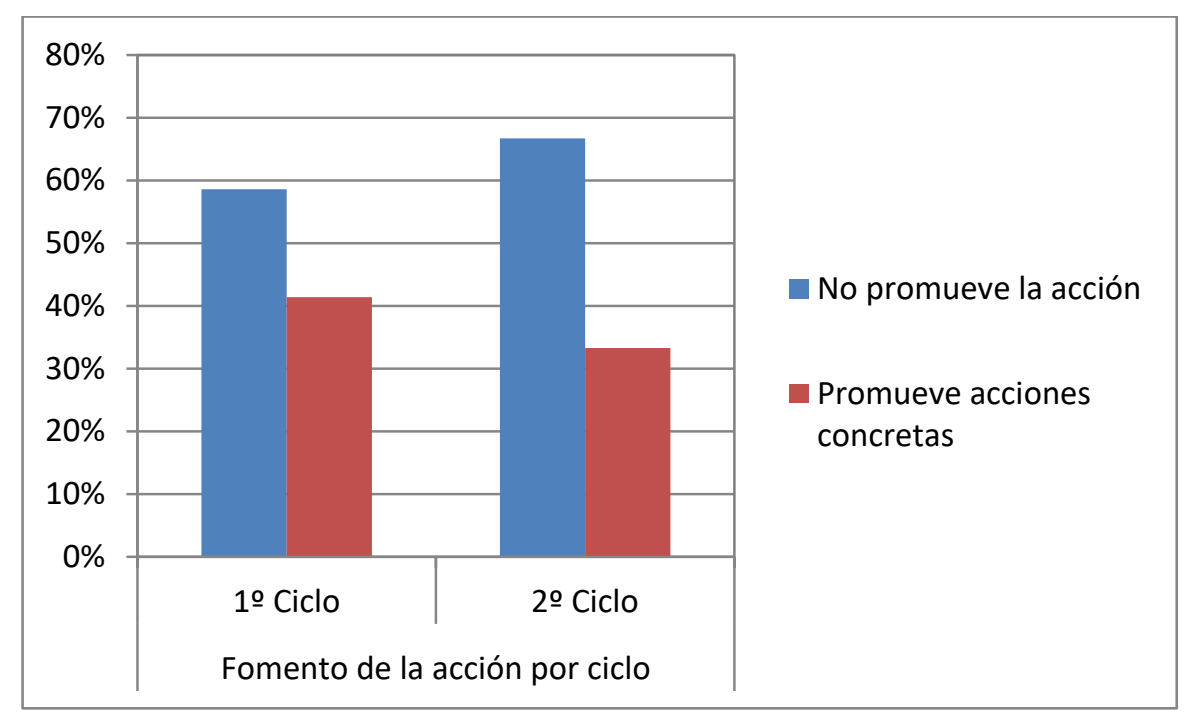

Fuente: elaboración propia

Los datos revelan que son los manuales de ciencias naturales los que exponen una actitud más crítica hacia la acción humana sobre los ecosistemas y avivan tanto valores como acciones de respeto medioambiental, que se incluyen entre los objetivos didácticos de los propios libros. Por su parte, los libros de ciencias sociales apenas recogen entre sus páginas consideraciones que pongan en tela de juicio las acciones humanas sobre el medio ambiente, aunque en algunos se fomenta un uso adecuado y responsable del uso del agua, se incentiva el reciclado y la reducción de la contaminación... En otras ocasiones, se invisibiliza la acción destructora de los países desarrollados, a la vez que se realza la de los países en vías de desarrollo.

Para trabajar valores y promover acciones se introducen secciones como "Conciénciate", "Ten iniciativa" o "Soluciones globales", que tratan de sensibilizar ambientalmente. No obstante, estas secciones, tal como ya indicamos, se ubican en apartados al final de la unidad didáctica, lo que supone que no es posible trabajarlos en un curso escolar apremiado por un calendario muy ajustado y por una evaluación que valora, de manera extremada, los contenidos conceptuales y no tanto las competencias y valores.

La presencia de valores socioambientales aumenta a lo largo de los ciclos educativos. El Seminario Internacional de Educación Ambiental de Belgrado (1975) estableció que el primer objetivo de la educación ambiental es la generación de conciencia, y para ello no hay edades limitantes, sólo a partir de ella se pueden promover medidas y proyectos exitosos. Si bien, como contradicción, detectamos que el fomento de medidas de acción y participación retrocede en el segundo ciclo, 
sobre todo en cuarto curso, más vinculada a la enseñanza de conocimientos ecocientíficos que a la implicación de acciones de responsabilidad y conservación.

Figura 8. Distribución del fomento de la acción por curso

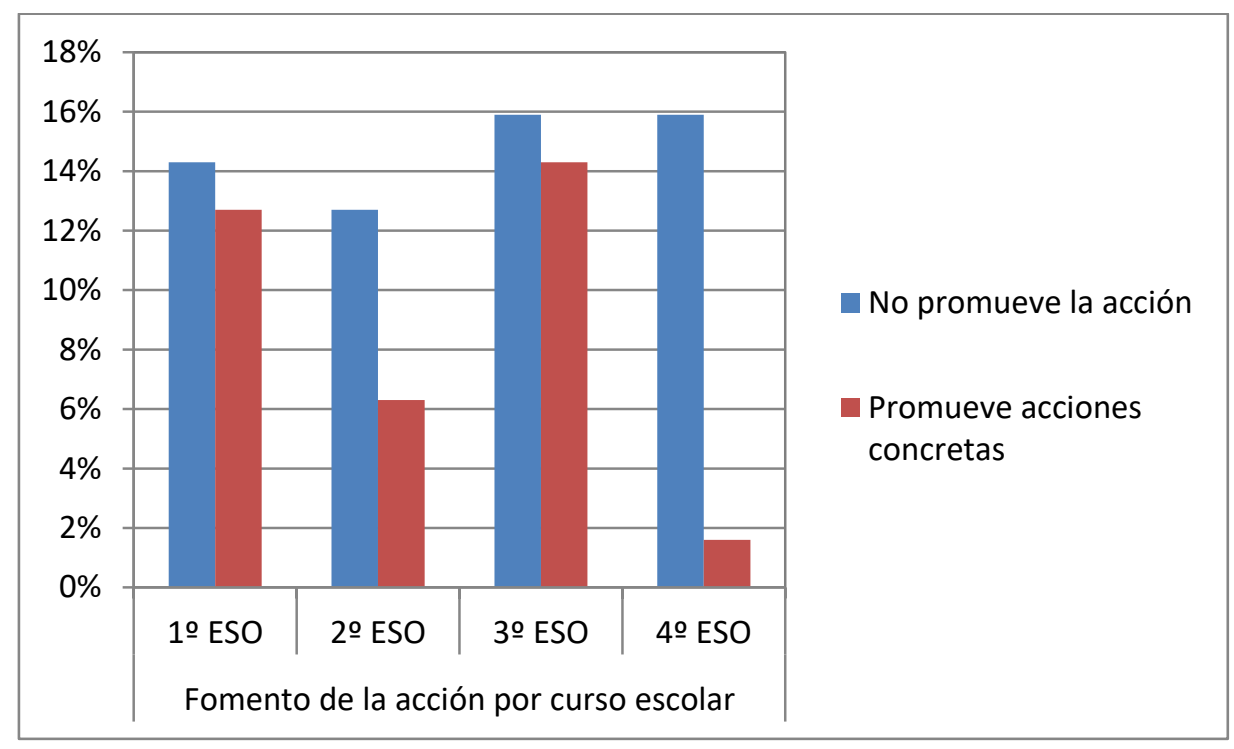

Fuente: elaboración propia

\subsection{Actividades y recursos didácticos para la educación a mbiental}

El análisis de las actividades y los recursos didácticos de los manuales permite deducir el tipo de aprendizaje que se pretende, así como el enfoque con el que se presenta la problemática ecológica. En relación con las actividades, las clasificamos en dos tipos: 1) Actividades básicamente memorísticas, dedicadas a que el alumnado desarrolle la capacidad memorística, a través de ejercicios que ponen a prueba el aprendizaje memorístico (repetir lo estudiado) y el análisis (analizar y comprender lo estudiado); y 2) Actividades de indagación, dedicadas a la búsqueda de información más allá de la que encuentra en el texto, ya sea en otros documentos especializados, en la prensa, en internet, audiovisuales, salidas extraescolares, etc., y que ayude al estudiante a construir su propio aprendizaje y a conectar la información del propio texto con sus experiencias extraescolares. Por tanto, estas últimas actividades presuponen el uso de otros recursos didácticos.

Otra de las cuestiones claves a examinar es el diseño de actividades en grupo, buscando la cooperación y colaboración, el intercambio de ideas y opiniones, la búsqueda de soluciones colectivas, etc., en contraposición con modelos de aprendizajes individualistas que persiguen mayoritariamente aprendizajes memorísticos. 
La revisión de las tareas recogidas en los manuales, basada no solo en la cuantificación sino también en una valoración cualitativa de cada una de las cuestiones planteadas, revela un predominio de las actividades que fomentan, en mayor medida, la retención de información a través de cuestiones que deben resolverse tras la lectura del propio libro de texto, que buscan reforzar lo aprendido, realizar cálculos y análisis, estructurar u organizar las diferentes ideas del texto. Por su parte, las actividades experimentales o de indagación que permitan al alumnado establecer relaciones de predicción, observación y explicación son insuficientes en ambas materias y ciclos educativos. Este tipo de actividades son más frecuentes en la materia de ciencias naturales sobre ciencias sociales y, de manera llamativa, en el primer ciclo sobre el segundo. Nuevamente, destacamos el déficit de actividades de investigación en cuarto curso y también en segundo, en consonancia con la deficiente promoción de actitudes críticas y el fomento de comportamientos más ecológicos y, tal vez, asociado a una mayor exigencia conceptual a los alumnos de los últimos cursos de los ciclos educativos.

Son muy puntuales las actividades para realizar en grupo o pareja, diseñadas en un contexto de colaboración, intercambio de ideas y reflexiones entre compañeros, a través de discusiones en grupo que permitan ejercitar el poder de la argumentación y el debate como método de aprendizaje y de responsabilidad. Este tipo de actividades capacitan, a su vez, en las competencias sociales y ciudadanas, así como en las de comunicación a través del intercambio de ideas.

Figura 9. Distribución de las actividades por ciclos, cursos y asignaturas

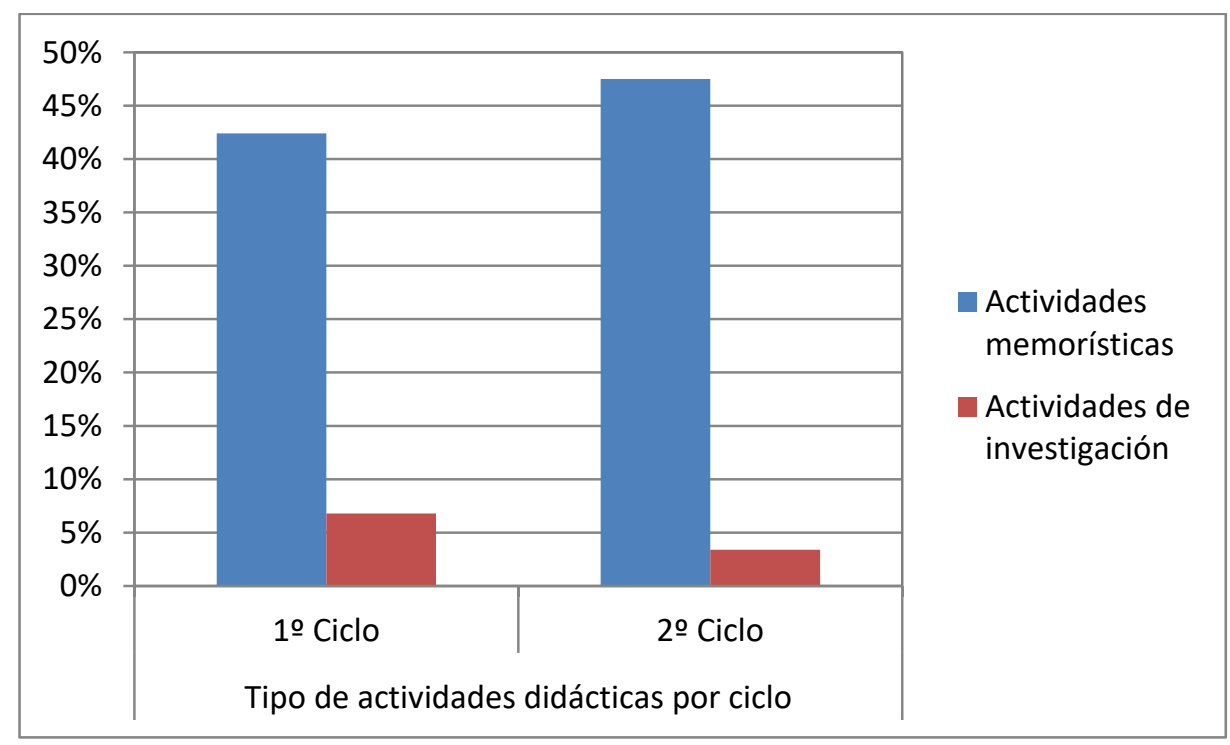


Figura 9. Continuación
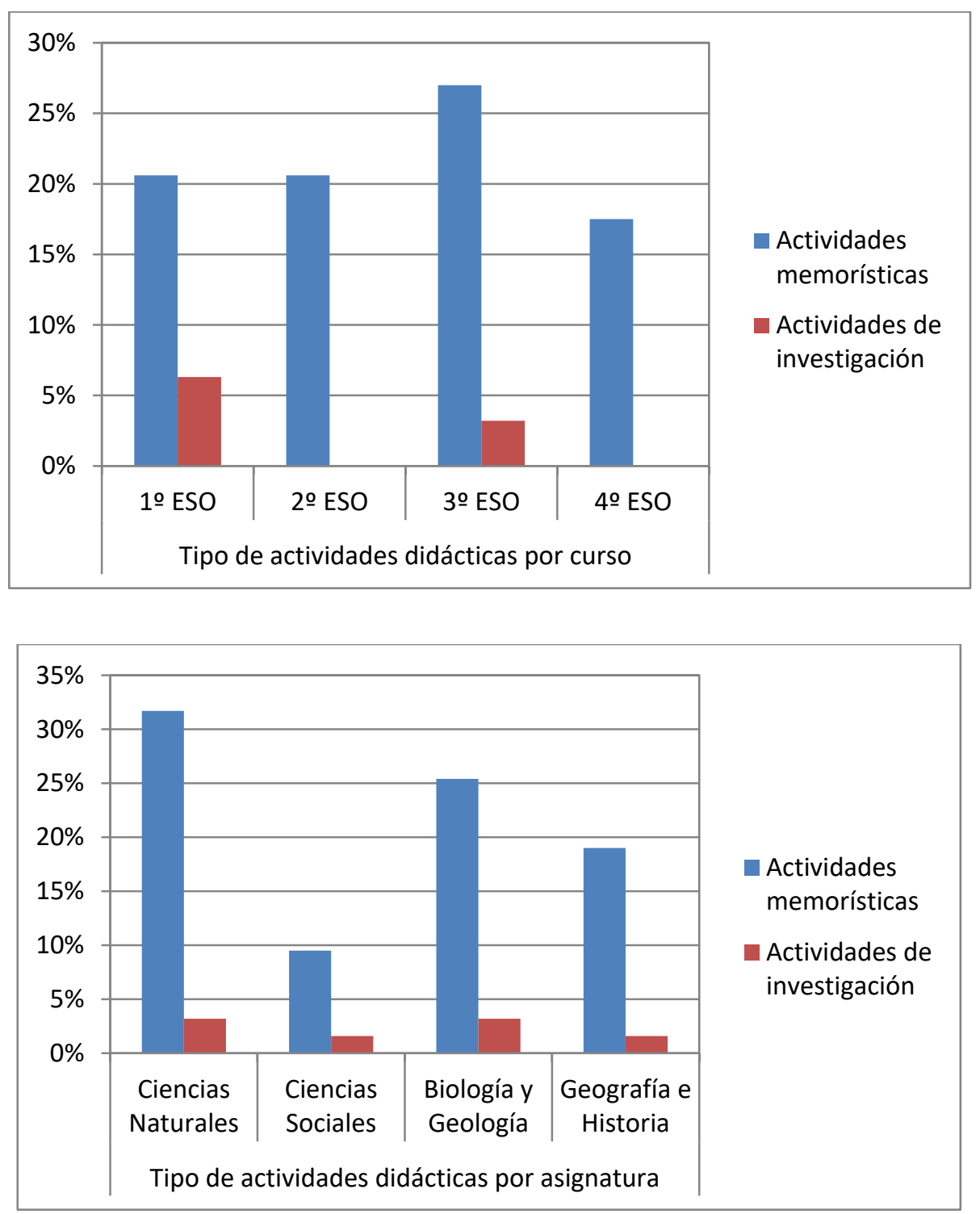

Fuente: elaboración propia

En este mismo sentido, se hace un abusivo uso de los recursos tradicionales en el proceso enseñanza-aprendizaje, los conocimientos se adquieren a través del propio libro de texto. Si bien, suelen ser frecuentes los enlaces a páginas web especializadas en temas medioambientales, sobre todo en los libros digitales, con el fin de consultar audiovisuales o, en menor caso, la proyección de películas o noticias de prensa. En estos casos, el material consultado reitera lo que ya se recoge en los manuales, y se desaprovecha la oportunidad de conocer otras opiniones e interpretaciones que instiguen al planteamiento de dudas, curiosidades y la construcción de juicios argumentados. 
Las propuestas de salidas o excursiones a la naturaleza son muy puntuales, a pesar de las oportunidades que ofrecen de integración entre la realidad, la práctica y la información aportada en los manuales. Además, estimulan los aprendizajes basados en experiencias directas, analizando la realidad, las causas y consecuencias que las acciones humanas tienen sobre el medio ambiente, promoviendo no solo la conciencia del problema sino también la búsqueda de posibles soluciones.

Por otra parte, mientras las tareas de papel y lápiz, relacionadas con la adquisición y clasificación de información, se localizan en las mismas páginas donde se detallan los contenidos conceptuales, esas que diariamente deben realizar los alumnos y alumnas como repaso de lo aprendido, aquellas otras dirigidas al desarrollo de la indagación y experimentación se encuentran en los apartados finales de las unidades didácticas, en los dedicados a trabajar tanto procedimientos como actitudes. Por tanto, difíciles de atender en un calendario escolar muy ajustado.

En definitiva, se observa que tanto las actividades como los recursos didácticos no fomentan la cooperación, ni tampoco los aprendizajes activos y participativos ni las experiencias directas. Al contrario, revelan un enfoque muy antropocéntrico de los contenidos medioambientales, desde una orientación alejada de propuestas pedagógicas que favorezcan los cambios en los valores y percepciones del medio ambiente, de los ecosistemas, así como el desarrollo de acciones más respetuosas con el entorno.

\section{Conclusiones}

Que los contenidos medioambientales y la educación ambiental figuren en los manuales escolares es una necesidad imperante, no solo porque así se recoge en el currículo educativo, sino sobre todo porque conocer el contexto ambiental es imprescindible para comprender la complejidad de los ecosistemas, mejorar la sensibilización ciudadana y contribuir a la resolución de los problemas ambientales que a día de hoy afectan tanto al propio ser humano como a toda la biodiversidad del planeta. A pesar de ello, entendemos que, tal como se enfocan estas cuestiones en los libros de texto, no se consigue el objetivo fundamental de la educación ambiental: capacitar para la acción (García Gómez y Martínez Bernat, 2010).

Los contenidos relacionados con el medio ambiente, entendido como la interrelación entre la naturaleza y las sociedades, están presentes en todos los libros de texto, tanto en la materia de ciencias naturales como de ciencias sociales, si bien, su presencia no suele superar el $20 \%$ ni siquiera en los libros de Biología y Geología. No obstante, la principal cuestión no es el porcentaje de su presencialidad, aunque se recomienda una mayor presencia sobre todo en los manuales 
correspondientes a las ciencias sociales, sino, a la visión con la que se transmiten los conocimientos, visión que se refleja en los conceptos, valores, procesos y técnicas.

Está claro que estudiar y comprender cómo funcionan los ecosistemas así como los distintos aspectos de la problemática ecológica no es fácil, pero aún resulta más complicado cuando se exponen desde miradas reduccionistas que dificultan la comprensión de los fenómenos y procesos, a la vez que se diluyen las relaciones causa-efecto y se invisibilizan algunos factores.

La educación ecocientífica que muestran los manuales de Educación Secundaria está lejos del desarrollo de habilidades cognitivas dentro de una perspectiva constructivista. La exposición de verdades científicas absolutas, más dirigidas a la memorización y clasificación, es más propia de corrientes positivistas, al igual que la falta de conexión entre saber y acción que reflejan, pues tal como señala Sauvé (2010, p. 10) "acción y reflexión no son ya etapas separadas, aisladas... Ser y actuar son indisociables en nuestra dinámica de vida". En este sentido es necesario estimular el sentido crítico, basado en la búsqueda de informaciones válidas, desarrollar en los alumnos capacidades argumentativas para que puedan reconocer la complejidad, la incertidumbre, y actuar en relación a los problemas medioambientales.

Los contenidos ecocientíficos en los libros de texto de Educación Secundaria se reducen a definiciones, de tal manera que aspectos como desarrollo sostenible, efecto invernadero, cambio climático se presentan como verdades absolutas e inalterables, siguiendo un modelo de enseñanza alejado del constructivismo que aboga por la participación e implicación del estudiante en su propio aprendizaje, con especial énfasis en estimular tanto la reflexión como su capacidad de análisis. Entendemos que estas propuestas limitan el desarrollo de las habilidades cognitivas del alumnado, por lo que deben ser sustituidas por estrategias de enseñanza que permitan a los estudiantes la búsqueda de información, su selección y clasificación, así como la comparación y contrastación, con el fin de identificar factores, establecer relaciones de causalidad, y fomentar las discusiones en las que deban exponer sus ideas y confrontarlas con sus compañeros e incluso con las de los profesores para probar su coherencia (Ceballos, Correa y Batista, 2002; García-Rodeja y De Lima, 2012).

Por otra parte, observamos que, a veces, los contenidos actitudinales se presentan de manera descontextualizada; o bien no se muestra la estrecha relación entre los problemas medioambientales y la acción humana, o bien se hace, pero se asume esa responsabilidad como un mal necesario. La separación de los contenidos técnico-científicos de los axiológicos que se recogen, bien en unidades didácticas diferentes al final del libro, o bien al final de cada una de las unidades en bloques o apartados distintos, dificulta la reflexión y comprensión de la problemática ambiental. 
En consonancia con ese entendimiento de la educación ambiental como contenido más que como proceso y actitud, se diseñan actividades de enseñanza-aprendizaje dirigidas a aprendizajes memorísticos por encima de las de indagación que contribuyan al desarrollo de habilidades de argumentación y razonamiento. Sorprende, igualmente, la escasa presencia de actividades en grupo para fomentar la cooperación y la colaboración en el proceso de aprendizaje, imprescindibles además en el valor comunitario del medio natural y en el compromiso de solidaridad ambiental que la educación debe promover.

Un proceso de enseñanza-aprendizaje basado en actividades que conlleven la formulación de preguntas, la elaboración de hipótesis, la búsqueda y selección de informaciones válidas, la construcción de respuestas, la defensa de argumentaciones, la participación en debates así como las reflexiones críticas y autocríticas, supondría: por una parte, la comprensión de los principios científicos (complejidad, multicausalidad e interrelación, dinamismo, analogía), que permitiría valorar y entender el papel de la ciencia en la construcción de los conocimientos científicos; y, por otra, la sensibilización y la implicación en acciones y medidas de conservación y protección, en definitiva, una educación para la ecociudadanía.

Los libros de texto deberían ser una guía tanto para el docente como para el alumnado, que planteen actividades diversas, imaginativas, motivadoras y colaborativas, que estimulen el interés de los jóvenes y que faciliten el trabajo en grupo. Deben apostar, asimismo, por recursos variados, tales como páginas web, blogs, documentales o películas, revistas y periódicos, salidas y excursiones, que hagan uso de los medios digitales, pero también de las posibilidades que el propio entorno ofrece, incentivando, a su vez, los proyectos de innovación didáctica.

Por otra parte, la transmisión de conocimientos teóricos y prácticos no promueve cambios de comportamiento medioambientales, siendo imprescindible una interiorización de ciertos valores, pues son estos los que conllevan comportamientos ecológicos y la adscripción de responsabilidad (Aguilar-Luzón, García-Martínez, Monteoliva-Sánchez \& Salinas, 2006; Corraliza \& Martín, 2000). En este sentido, consideramos que el excesivo peso otorgado a la definición de conceptos así como el tipo de actividades diseñadas no generan valores de responsabilidad ambiental, de respeto y cuidado, de compromiso y gratitud entre los adolescentes. Para incentivar la acción y la participación colectiva, consideramos, al igual que señala Novo (2009, p. 213), que la educación debe "movilizar no sólo los aspectos racionales, sino también todo el ámbito de los afectos, de los valores y de la mirada estética sobre el mundo". En este mismo sentido se expresan Ortega y Mínguez (2003, p. 290): "se hace difícil otra educación ambiental si no se atiende, junto a los conocimientos, el ámbito afectivo y volitivo de las personas". Pero para ello es necesaria también 
una ruptura de los conceptos "progreso" y "consumismo". Tal como señala Caride (2001, p. 3), una educación ambiental

[...] que promueve e instituye discursos que proyectan un cambio en las sensibilidades y valores que han de orientar la actividad humana en relación con el medio ambiente, dirigida a la adquisición de conocimientos ecológicos y a una toma de conciencia crítica, desde la que analizar los procesos socio-ambientales y sus consecuencias para el futuro del Planeta, habilitando actitudes y comportamientos coherentes con la ética que demanda un desarrollo sostenible y solidario.

La asunción de responsabilidades y el desarrollo de acciones participativas, deben ser los fines principales de la educación ambiental, tal como Joaquín Araújo sugiere con estas palabras:

Convendría recordar también que más larga es la vida de lo sugerido que de lo inculcado. Que no se trata solo de conocer aspectos más o menos profundos del funcionamiento de los ecosistemas. Ni siquiera de las constructivas apuestas por una conducta más solidaria. Es todo eso y más. Es la apertura de conversaciones para la construcción de una ética más allá de los códigos y más cerca, por tanto, de un estilo de vida, de una conducta equidistante del sentimiento-intuición y del pensamientoreflexión (Araújo 2000, p. 97).

En definitiva, el análisis de los manuales escolares para la ESO, de las diez editoriales de uso más común en nuestro país, refleja que si bien las problemáticas ambientales son temas a tratar en todos ellos, se afrontan con mayor o menor detalle en los libros de Ciencias Naturales que en los de Ciencias Sociales. Pensamos que esta diferencia se debe al enfoque con el que se presentan estas cuestiones, más como conocimientos a memorizar, que desde una visión socioambiental, que busque la comprensión y reflexión.

Publicaciones previas relacionadas, igualmente, con el análisis de libros de texto, adscritos tanto a la LOGSE como a LOE (Del Carmen \& Jiménez, 1997; García \& Martínez, 2009, 2010; Martínez \& García, 2003; Occelli \& Valeiras, 2013), bien para Educación Secundaria como Primaria, evidencian estas mismas conclusiones que se resumen en un proceso enseñanza-aprendizaje aún muy teórico y memorístico.

Entendemos que los manuales escolares deben secundar posturas que revelen el valor intrínseco de todas las especies y ecosistemas, visiones que destaquen las repercusiones negativas que la acción humana tiene sobre el medio ambiente en general, no solo los problemas que generan para la vida humana, sino para el resto de seres vivos con los que compartimos el planeta. Esto solo es 
posible haciendo participar al alumno en su propio proceso de aprendizaje, a través de argumentaciones y razonamientos, en cooperación y disfrutando del propio entorno que le rodea, dotándolo de valores morales y éticos, pues no son tan importantes los conocimientos como la generación de conciencia.

Finalmente, conviene señalar que aunque los manuales escolares analizados están adscritos a la LOE y, por tanto, no están ya vigentes, consideramos que las conclusiones expresadas pueden ofrecer una oportunidad para que la publicación de futuros manuales escolares atienda los principios y valores que la educación ambiental y la sociedad están demandando actualmente. Además, tal como ya se ha indicado, este estudio puede ser un referente para comparaciones entre los manuales vigentes, adscritos a la LOMCE, y los adscritos a otras leyes educativas anteriores, planteando un recorrido histórico de la educación ambiental en los diferentes currículos educativos, desde su implantación con la LOGSE hasta la LOMCE, y su tratamiento en los libros de texto, valorando si hay una cierta continuidad en los enfoques, procesos y técnicas, o si, por el contrario, se hacen eco de los debates y dilemas éticos ambientales sobre los que la sociedad, poco a poco, empieza a reflexionar (Burgui \& Chuvieco, 2017).

Agradecimientos: Esta investigación es parte del proyecto de investigación Valores y enfoques ambientales en la Enseñanza Secundaria Obligatoria realizado en el marco del convenio de colaboración entre la Cátedra de Ética Medioambiental Fundación Tatiana Pérez de Guzmán el Bueno-Universidad de Alcalá y la Universidad de Extremadura.

Declaración responsable: Las/os autoras/es declaran que no existe ningún conflicto de interés en relación a la publicación de este artículo. Ana María Hernández Carretero y Federico Velázquez de Castro se han encargado de los análisis de los libros de los distintos manuales escolares. Previamente, para ello, elaboramos una ficha de trabajo para homogeneizar los criterios de análisis, en la que también participaron el resto de los autores. Mario Burgui se centró en el estudio cuantitativo de todos los datos y valoraciones obtenidos de los manuales escolares, utilizando para ello el programa SPSS. Asimismo, se ha encargado del diseño de los gráficos. José María Corrales Vázquez ha revisado el curriculum educativo de la LOE para la Educación Secundaria, así como de todas las declaraciones de la UNESCO sobre medio ambiente. Finalmente, todos hemos contribuido a la selección de las principales editoriales para la adquisición de los manuales escolares y, por supuesto, a la revisión de bibliografía, redacción y revisión del texto. Ana $M^{a}$ Hernández Carretero ha desarrollado, además, la función de coordinación de todos los análisis y valoraciones de este estudio para su publicación. 


\section{Bibliografía}

Aguilar-Luzón, M. C., García-Martínez, J. M., Monteoliva-Sánchez, A., \& Salinas, J. M. (2006). modelo del valor, las normas y las creencias hacia el medio ambiente en la predicción de la conducta ecológica. Medio Ambiente y Comportamiento Humano, 7(2), 21-44.

Apple, M. W. (1993). El libro de texto y la política cultural. Revista de Educación, 301, 109-126. DOI: 10.4438/1988-592X-0034-8082-RE

Araújo, J. (2000). Ecos...Lógicos. Para entender la ecología. Madrid: Maeva Ediciones.

Billbeny, N. (2010). Ecoética. Ética del medio ambiente. Barcelona: Aresta.

Botey, J. (2013). Anàlisi dels llibres de text de Ciències Socials des d'una perspectiva de pau (Quart D'ESO, 2008-2011). Barcelona: Institut Català Internacional per la Pau.

Burgui, M., \& Chuvieco, E. (2017). Dimensiones éticas en los dilemas ambientales. Estudio de casos. Madrid: Ediciones Internacionales Universitarias.

Caride, J. A. (2001). La Educación Ambiental en el Desarrollo Humano: horizontes para la sustentabilidad ecológica y la responsabilidad social. Retrieved from http://www.mapama.gob.es/es/ceneam/articulos-de-opinion/2001-10caride_tcm30163522.pdf

Carvalho, S., \& Clément, P. (2007). Educação em biologia, educação para a saúde e educação ambiental para uma melhor cidadania: análise de manuais escolares e concepções de professores de 19 países (europeus, africanos e do próximo oriente). Revista Brasileira de Pesquisa em $\begin{array}{llll}\text { Educação em } \quad \text { Ciências, } & 7(2) . & \text { Retrieved }\end{array}$ from http://revistas.if.usp.br/rbpec/article/viewFile/67/60

Ceballos, E., Correa, N., \& Batista, L. (2002). Competencias argumentativas sobre el Medio Ambiente en Primaria y Secundaria: implicaciones para la educación ambiental. Medio Ambiente y Comportamiento Humano, 3(1), 167-186.

Corraliza, J. A., \& Martín, R. (2000). Estilos de vida, actitudes y comportamientos ambientales. Medio Ambiente y Comportamiento Humano, 1(1), 31-56.

Choppin, A. (1992). Les Manuels scolaires: Histoire et actualité. Paris: Hachette éducation.

Chuvieco, E., \& Martín, M. A. (2015). Cuidar la Tierra: razones para conservar la naturaleza. Madrid: Digital Reasons. 
De Paula, F., De Las Heras, M. A., Romero, R., \& Cañal, P. (2014). El conocimiento escolar sobre los animales y las plantas en primaria: Un análisis del contenido específico en los libros de texto. Revista Electrónica de Enseñanza de las Ciencias, 13(1), 97-114.

De Puelles Benítez, M. (2007). La política escolar del libro de texto en la España contemporánea. Avances en supervisión educativa. Revista de la Asociación de Inspectores de Educación de España, 6. Retrieved

from http://www.adide.org/revista/index.php?option=com_content\&task=view\&id=198\&ltemid=4 $\underline{7}$

Del Carmen, L., \& Jiménez, M. P. (1997). Los libros de texto: un recurso flexible. Alambique, 11, 7-14.

Eisner, E. W. (1992). Curriculum ideologies. In P. W. Jackson (Ed.), Handbook of Research on Curriculum (pp. 302-326). New York: Macmillan.

Ferguson, J., Collison, D., Power D., \& Stevenson, L. (2006). Accounting textbooks: exploring the production of a cultural and political artifact. Accounting Education, 15(3), 243-260.

García, J., \& Martínez, F.J. (2009). Análisis del tratamiento didáctico de la biodiversidad en los libros de texto de Biología y Geología en Secundaria. Didáctica de las Ciencias Experimentales y Sociales, 23, 109-122.

García, J., \& Martínez, F. J. (2010). Cómo y qué enseñar de la biodiversidad en la alfabetización científica. Enseñanza de las Ciencias, 28(2), 175-184. doi: 10.5565/rev/ec/v28n2.212

García-Rodeja, I., \& Lima De Oliveira, G. (2012). Sobre el cambio climático y el cambio de los modelos de pensamiento de los alumnos. Enseñanza de las Ciencias, 30(3), 195-218. DOI $10.5565 / \mathrm{rev} / \mathrm{ec} / \mathrm{v} 30 \mathrm{n} 3.695$

Gimeno, J. (2005). El currículum: ¿Los contenidos de la enseñanza o un análisis de la práctica? In J. Gimeno, \& A. I. Pérez (Eds.), Comprender y transformar la enseñanza (137-169). Madrid. Morata.

González, M. C. (1996). Principales tendencias y modelos de la Educación Ambiental en el sistema escolar. Revista Iberoamericana de Educación, 11, 13-74.

Marcos, A. (2001). Ética Ambiental. Valladolid: Universidad de Valladolid. 
Martínez, C., \& García, S. (2003). Las actividades de Primaria y ESO incluidas en libros escolares. ¿Qué objetivo persiguen? ¿Qué procedimientos enseñan? Enseñanza de las Ciencias, 21(2), $243-264$.

Marrón Gaite, M.J. (2011). Educación geográfica y formación del profesorado. Desafíos y perspectivas en el nuevo Espacio Europeo de Educación Superior (EEES). Boletín de la Asociación de Geógrafos Españoles, 57, 313-341. Available in http://www.agegeografia.es/ojs/index.php/bage/article/view/1386

Matthews, M. R. (2012). Changing the focus: From nature of science (NOS) to features of science (FOS). In M. S. Khine (Ed.), Advances in Nature of Science Research. Concepts and Methodologies (pp. 3-26). Heidelberg: Springer Dordrecht.

Muñoz, L., \& Rubio, L. (2013). Análisis de libros de textos escolares. Conocimiento del Medio Natural Social y Cultural. Toledo: Facultad de Educación de Toledo.

Murga, M. A. (2009). La Carta de la Tierra: un referente de la Década por la Educación para el Desarrollo Sostenible. Revista de Educación, extr. vol, 239-262. Retrieved from http://www.revistaeducacion.mec.es/re2009/re2009_11.pdf

Novo, M. (1996). La educación ambiental formal y no formal: dos sistemas complementarios. Revista Iberoamericana de Educación, 11, 75-102.

Novo, M. (2009). La educación ambiental, una genuina educación para el desarrollo sostenible. Revista de Educación, extr. vol, 195-217. Retrieved from http://www.revistaeducacion.mec.es/re2009/re2009 09.pdf

Novo, M., \& Murga M. A. (2010). Educación ambiental y ciudadanía planetaria. Revista Eureka sobre enseñanza y divulgación de las ciencias, 7(4), 179-186. Retrieved from http://rodin.uca.es/xmlui/bitstream/handle/10498/8934/1_Novo_Murga_2010.pdf?sequ $\underline{\text { ence }=1}$

Occelli, M., \& Valeiras, N. (2013). Los libros de texto de ciencias como objeto de investigación: una revisión bibliográfica. Enseñanza de las Ciencias, 31(2), 133-152. DOI $10.5565 / \mathrm{rev} / \mathrm{ec} / \mathrm{v} 31 \mathrm{n} 2.761$

Pérez, M. Á., Pérez, M., \& Quijano, R. (2009). Valoración del cambio de actitudes hacia el medio ambiente producido por el programa didáctico "EICEA" en los alumnos de Educación Secundaria Obligatoria (14-16 años). Revista Electrónica de Enseñanza de las Ciencias, 8(3). Retrieved from http://reec.uvigo.es/volumenes/volumen8/ART14_Vol8_N3.pdf 
Sauvé, L. (2010). Educación científica y educación ambiental: un cruce fecundo. Enseñanza de las Ciencias, 28(1), 5-18.

UNESCO (2007). Decenio de las Naciones Unidas de la Educación para el Desarrollo Sostenible 2005-2014: El Decenio en pocas palabras. Retrieved from http://unesdoc.unesco.org/images/0014/001416/141629s.pdf

UNESCO (1972). Declaración de Estocolmo sobre el medio ambiente humano. Conferencia de las Naciones Unidas sobre el Medio Ambiente Humano, 16 de junio de 1972. Stockholm: UNESCO.

UNESCO (1975). Carta de Belgrado. Seminario Internacional de Educación Ambiental de Belgrado. Belgrado: UNESCO.

UNESCO (1977). Declaración de la Conferencia Intergubernamental sobre Educación ambiental. Tbilisi: UNESCO.

UNESCO (1987). Elementos para una Estrategia Internacional de acción en materia de educación y formación ambientales para el decenio de 1990 (Doc. ED-87/Conf.402/Col.1). Congreso Internacional UNESCO-PNUMA sobre la educación y la formación ambientales. Moscow: UNESCO.

UNESCO (1992). Cumbre de la Tierra de Río de Janeiro. Río de Janeiro: UNESCO.

UNESCO (2002). La Cumbre Mundial sobre el Desarrollo Sostenible. Johannesburgo: UNESCO.

UNESCO (2006). Decenio de las Naciones Unidas de la Educación para el Desarrollo Sostenible 2005-2014: El Decenio en pocas palabras. UNESCO. Retrieved from http://www.unesco.org/new/en/education/themes/leading-the-internationalagenda/education-for-sustainable-development/

UNESCO (2012). Forjar la educación del mañana. Decenio de las Naciones Unidas de la Educación para el Desarrollo Sostenible (Informe 2012, abreviado). Retrieved from http://unesdoc.unesco.org/images/0021/002191/219155s.pdf

Ortega, P., \& Mínguez, R. (2003). Educar para una cultura medioambiental. Revista de Educación, extr. vol., 271-294. DOI: 10.4438/1988-592X-0034-8082-RE

Velázquez De Castro, F. (2007). Los valores revolucionarios de la educación ambiental. Granada: Grupo Editorial Universitario. 
Woodward, A., \& Elliott, D. L. (1990). Textbook use and teacher professionalism. In D. L. Elliott, \& A. Woodward (Eds.), Textbooks and schooling in the United States (pp. 178-193). Chicago: The University of Chicago Press.

\section{Anexo I. Ficha de recogida de datos}

\begin{tabular}{|c|c|c|}
\hline EXTENSIÓN DEL TEMA & \multicolumn{2}{|l|}{ (Páginas) } \\
\hline UBICACIÓN & \multicolumn{2}{|c|}{ Bloque, Tema, Punto... } \\
\hline \multicolumn{3}{|l|}{ TÍTULO DEL TEMA } \\
\hline CONTENIDOS CONCEPTUALES & $\begin{array}{l}\text { ECOLÓGICOS- } \\
\text { CIENTÍFICOS } \\
\text { SOCIALES- } \\
\text { ECONÓMICOS }\end{array}$ & $\begin{array}{l}\text { Presentados desde un } \\
\text { enfoque: } \\
\text { - Muy Antropocéntrico } \\
\text { - Bastante } \\
\text { Antropocéntrico } \\
\text { - Medio } \\
\text { - Bastante Biocéntrico } \\
\text { - Muy Biocéntrico }\end{array}$ \\
\hline CONTENIDOS ACTITUDINALES & \multicolumn{2}{|c|}{ CRÍTICOS CON LA ACCIÓN HUMANA } \\
\hline PROMUEVEN VALORES ÉTICOS & & \\
\hline FOMENTA LA PARTICIPACIÓN Y ACCIÓN & \multicolumn{2}{|l|}{$\mathrm{SI} / \mathrm{NO}$} \\
\hline ACTIVIDADES DIDÁCTICAS & \multicolumn{2}{|c|}{$\begin{array}{l}\text { MEMORÍSTICAS: } \\
\text { • Aplicación teórica } \\
\text { • Reforzar lo aprendido } \\
\text { • Clasificación información } \\
\text { DE INVESTIGACIÓN } \\
\text { • Experimento } \\
\text { - Investigación }\end{array}$} \\
\hline TRABAJOS & \multicolumn{2}{|c|}{$\begin{array}{l}\text { INDIVIDUALES } \\
\text { GRUPOS (COLABORACIÓN) }\end{array}$} \\
\hline RECURSOS DIDÁCTICOS & \multicolumn{2}{|c|}{$\begin{array}{l}\text { TEXTOS } \\
\text { INTERNET } \\
\text { VIDEOS } \\
\text { PRENSA } \\
\text { SALIDAS ESCOLARES } \\
\text { OTROS }\end{array}$} \\
\hline
\end{tabular}

